\title{
Complications of cochlear implantation surgery in Zagazig University Hospitals
}

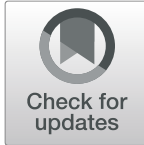

Alaa Eldin M. Elfeky, Adly A. Tantawy, Asmaa M. Ibrahim, Ibrahim M. Saber ${ }^{*}$ and Said Abdel-Monem

\begin{abstract}
Background: Cochlear implantation (Cl) has been established worldwide as the surgical treatment for individuals with bilateral severe to profound hearing loss. Complications due to surgery are minimal and are often encountered in cases with congenital anomalies of the temporal bone and inner ear. Complications in $\mathrm{Cl}$ are related to malfunctioning of the device or the process of wound healing. In most cochlear implant centers, as the surgeon's skill and clinical expertise in managing various cochlear implant cases improve with years of experience, the complication rates ideally come down over time.

This article is intended to describe the most common surgical complications of cochlear implantation in Zagazig University Hospitals. This retrospective study included 130 patients who underwent cochlear implantation in Zagazig University Hospitals from 2016 to 2018. The patients were 61 males and 69 females; their ages ranged between 2 and 6 years old with a mean age of 4.3. This study aims to provide feedback on the common complications of $\mathrm{Cl}$ surgery at our institution to help the reduction of its incidence in the future.

Results: One hundred thirty cases of cochlear implants were performed in our department between 2016 and 2018. Sixty complications were recorded, including 27 cases of minor and 21 cases of major complications. Minor complications were flap wound infection in 4 cases (3.1\%), chorda tympani nerve injury in 7 cases (5.4\%), postoperative vertigo and vomiting in 3 cases (2.3\%), injury of EAC in 7 cases (5.4\%), wound seroma/hematoma in 4 cases (3.1\%), and facial nerve twitching in 2 cases (1.5\%). Major complications were electrode extrusion in 2 cases (1.5\%), CSOM in 1 case (0.8\%), CSF leak in 8 cases (6.1\%), magnet migration in 3 cases (2.3\%), total facial nerve paralysis in 5 cases (3.8\%), and device failure in 2 cases (1.5\%).

Conclusion: The overall incidence of major complications is low. The majority of minor complications can be effectively managed with conservative measures. Cochlear implantation remains a safe and effective surgical procedure.
\end{abstract}

Keywords: Cochlear implantation, Minor complications, Major complications

\section{Background}

Nowadays, cochlear implantation is the only means of restoring partial hearing to patients with severe to profound sensorineural hearing loss not aidable with conventional amplification [1]. The operation provides people greater access to sound and improvement in their auditory abilities, speech understanding, and linguistic

\footnotetext{
* Correspondence: Ibrahimsaber25@yahoo.com

Department of Otorhinolaryngology, Faculty of Medicine, Zagazig University, Koliat Al Tob st, Shaibet an Nakareyah, Markaz El-Zagazig, Ash Sharqia Governorate 44519, Egypt
}

\section{Springer Open}

development [2]. The device is auditory prostheses designed to stimulate the cochlear nerve and to translate acoustic information into electric stimulation [3].

Implantation at an early age results in the best auditory-verbal outcomes [3].

Knowledge of the risks associated with cochlear implantation is important. As with any surgical procedure, a proportion of patients suffer postoperative complications and classified further as early vs late and major vs minor [4]. Early complications refer to those occurring during the week after surgery [4]. The minor
(0) The Author(s). 2021 Open Access This article is licensed under a Creative Commons Attribution 4.0 International License, which permits use, sharing, adaptation, distribution and reproduction in any medium or format, as long as you give appropriate credit to the original author(s) and the source, provide a link to the Creative Commons licence, and indicate if changes were made. The images or other third party material in this article are included in the article's Creative Commons licence, unless indicated otherwise in a credit line to the material. If material is not included in the article's Creative Commons licence and your intended use is not permitted by statutory regulation or exceeds the permitted use, you will need to obtain permission directly from the copyright holder. To view a copy of this licence, visit http://creativecommons.org/licenses/by/4.0/. 
complications are those that can be resolved either spontaneously or with conservative treatment and the major complications are those that require hospital admission, surgery, and later re-intervention [5].

The rate of major complications was not influenced by the etiology of deafness, sex, nor age at implantation [6]. Although most complications are only transient, few remain permanent and need intensive management.

Major complications such as problems during electrode bundle insertion, flap complications, peripheral facial paralysis, otomastoiditis, postoperative CSF fistula [7], implant sepsis, device failure, non-auditory stimulation, and meningitis are rare but serious complications [3].

Minor complications are transient peripheral facial paralysis; damage to the tympanic membrane; injury to the posterior wall of the external acoustic meatus during surgery, hemorrhage, chorda tympani nerve injury [7], balance problems, tinnitus, post-operative bleeding, altered facial sensation, facial swelling, otitis media, surgical emphysema, minor electrode mal-position, skin ulceration, granulation tissue bleeding, and pinna ulceration [6]. The aim of this study is to review the rate of complications at our institution and to give a basis to decrease the incidence of these complications in the future.

\section{Methods}

This retrospective study included 130 patients who underwent cochlear implantation in Zagazig University Hospitals from 2016 to 2018. The number of cases of complications was calculated in relation to the total number of cases. All patients had congenital HL since birth. All patients were diagnosed by audiological evaluation (aided audiometry, ABR, and otoacoustic emission) to have severe to profound bilateral SNHL. Radiological evaluation CT and MRI were done to all patients. A retrospective review of the patient's data was done including the patient's characteristics, surgery, outcome, and complications. Eight patients had congenital inner ear anomalies one common cavity, two IP1 (Fig. 1), and five IP2 (Fig. 2).

Ethics approval and consent to participate is applicable.
Selection criteria:

1. Have a profound hearing loss in both ears.

2. Get little or no benefit through the use of hearing aids over a time period of 6 months.

3. No medical or psychological contra-indication for surgery.

4. Realistic expectations by the patients and their parents.

Exclusion criteria:

1. Adults suffer from moderate to severe sensoryneural hearing loss.

2. Unilateral hearing loss.

3. Patients who suffer from post meningitis cochlear ossification.

4. Patients who underwent previous mastoid surgery at the same ear.

\section{Results}

The total number of cases for which cochlear implantation was performed at the Otorhinolaryngology Department is 130 cases between 2016 and 2018. The patients were 61 males and 69 females; their ages ranged from 2 to 6 years (Fig. 3).

\section{Surgical technique}

All the surgeries were carried out by the same group of surgeons using the standard technique of posterior tympanotomy. Two types of incision were used: extended end aural incision in 93 cases (71.5\%) and post-auricular incision in 37 cases (28.5\%).

\section{Postoperative care}

Patients have been followed up regularly with close monitoring of the level of consciousness, vital signs, light reflex, pupil size, and wound dressing. After surgery, patients were kept in the hospital for 2-3 days. An x-ray was done to verify the position of the electrode array. Parenteral antibiotics were given, compressive mastoid dressing was changed, and the patient was discharged with oral antibiotics. Sutures were removed on the tenth postoperative day and wound status was assessed for any
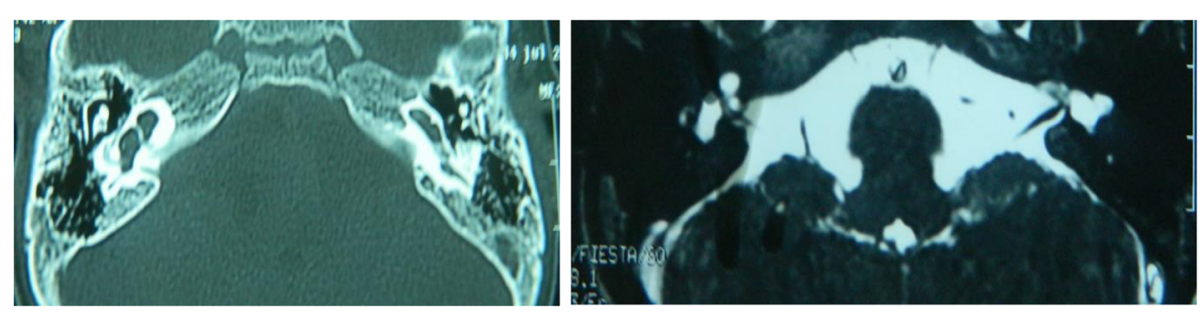

Fig. $1 C T$ and MRI of IP1 

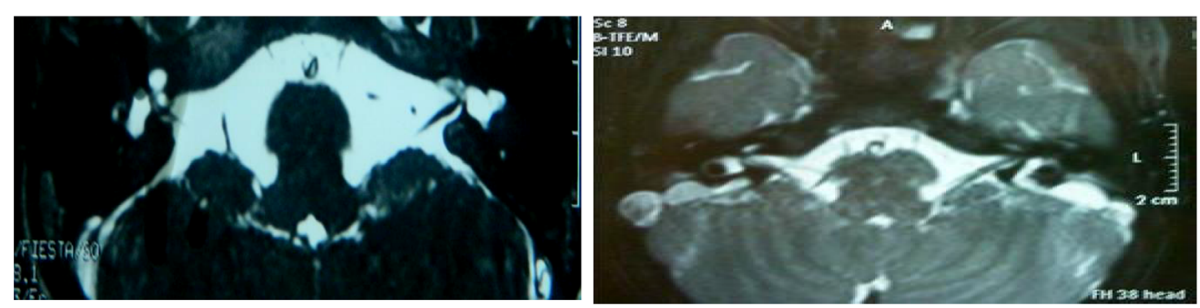

Fig. $\mathbf{2} C T$ and MRI of IP2

complication. Children were seen at the outpatient clinic at 1 month for the first activation of the cochlear implant. The mean follow-up time of the studied group was $14.7 \pm 5.3$ and ranged from 6 to 24 months.

\section{Complications}

\section{Minor complications}

Table 1 shows that $20.76 \%$ of the studied group had minor complications. Chorda tympani nerve injury and injury to EAC were the commonest minor complications (5.4\%) for each followed by wound infection and seroma/hematoma (3.1\%) for each, then vertigo/vomiting (2.3\%), and lastly, facial nerve twitching was (1.5\%) for each.

\section{Chorda tympani nerve injury}

Transient complaints were reported in 7 cases. This syndrome was defined as changes in taste, tongue paresthesia, or mouth dryness that developed postoperatively. The cases were treated by conservative management.

\section{Postoperative vertigo/vomiting}

The symptoms of vertigo were reported in 3 cases who manifested within the first postoperative day. The symptoms were resolved using medical treatment (e.g., steroids and vasodilators). Clinical assessment was done and treatment was given according to findings.

\section{Injury to EAC skin}

There were 7 cases of external auditory canal injury. The fenestrations were repaired using muscle, fascia, or cartilage taken from the tragus. The fenestrations healed well without complications.

\section{Wound infection}

Wound infection occurred in 4 cases. The surgical incision was red and swollen. They were manifested 2 weeks postoperatively. All of them were treated with IV antibiotics, wound debridement, flap revision procedure (1 case), and daily dressing, all were recovered well.

\section{Wound seroma/hematoma}

The hematoma was observed in 4 cases usually 1-2 days after the operation. A small hematoma was often managed via local pressure dressing, antibiotics, and symptomatic treatments. For more difficult hematoma (1 case), drainage was performed under a complete aseptic condition in addition to the above management. Generally, local conditions improved within half a month.

\section{Facial nerve twitching}

Two patients developed paresis on the operated side after surgery; these patients were treated by programming and by switching off the selective electrode. Complete resolution was seen in all patients.

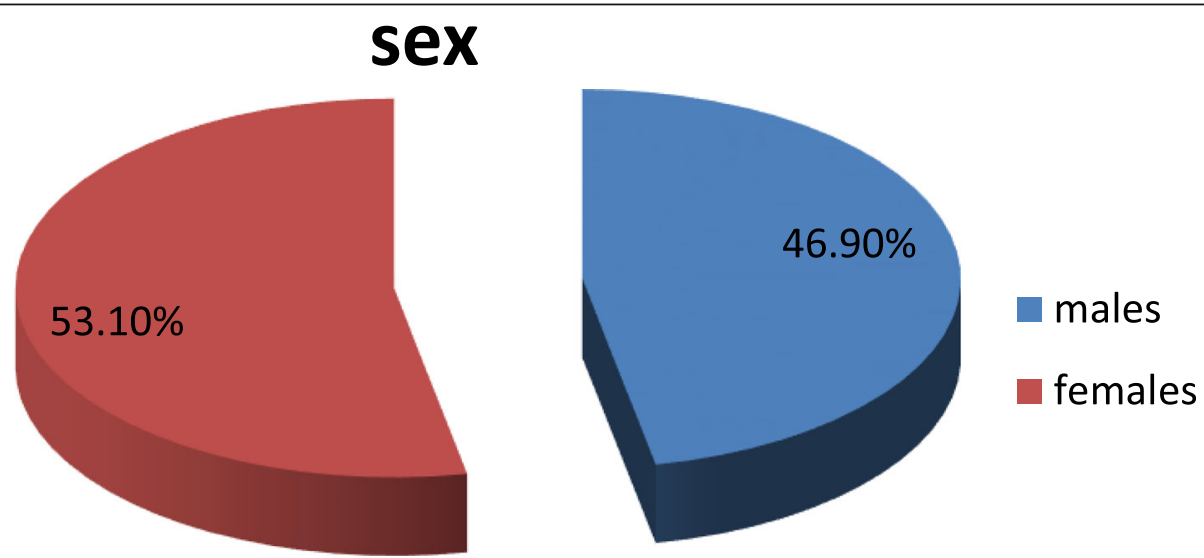

Fig. 3 Pie chart for sex distribution among the studied group 
Table 1 Minor complications among studied group

\begin{tabular}{lll}
\hline Minor complications & NO (130) & \% \\
\hline Chorda tympani nerve injury & 7 & $5.4 \%$ \\
VertigoNomiting & 3 & $2.3 \%$ \\
Injury to EAC & 7 & $5.4 \%$ \\
Wound infection & 4 & $3.1 \%$ \\
Seroma /hematoma & 4 & $3.1 \%$ \\
Facial nerve twitching & 2 & $1.5 \%$ \\
Total & 27 & $20.76 \%$ \\
\hline
\end{tabular}

\section{Major complications}

Table 2 shows that $16.1 \%$ of the studied group had major complications. CSF leak was the commonest major complications $(6.1 \%)$ followed by total facial nerve paralysis $(3.8 \%)$ then magnet migration $(2.3 \%)$, and electrode extrusion and device failure (1.5\%), and lastly, CSOM was the least complications $(0.8 \%)$ for each.

\section{Electrode extrusion}

Electrode misplacement occurred in 2 cases which was confirmed by postoperative CT. The device migrated antro-inferiorly and become below the incision, so the patient was revised under G.A and repositioning of the device in the seat, and fixation of the device was done, after that the electrode is extruded, by NRT there were non-functioning (open) electrodes.

\section{Transient facial nerve paralysis}

Transient facial nerve paralysis occurred in 5 patients. The patients were medically treated and all of them were improved and facial function became normal within 3 months of the operation.

\section{Device migration}

Three cases suffered from magnet migration due to trauma which required magnet reposition surgery (Fig. 4).

Table 2 Major complications among the studied group

\begin{tabular}{lll}
\hline Major complications & NO (130) & $\%$ \\
\hline Electrode extrusion & 2 & $1.5 \%$ \\
Total facial nerve paralysis & 5 & $3.8 \%$ \\
device migration & 3 & $2.3 \%$ \\
CSOM & 1 & $0.8 \%$ \\
CSF leak & 8 & $6.1 \%$ \\
Device failure & 2 & $1.5 \%$ \\
Total & 21 & $16.1 \%$ \\
\hline
\end{tabular}

\section{Chronic suppurative otitis media}

One patient experienced ear discharge and a sensation of pressure. A cholesteatoma was detected. Treatment was done by explantation and staged revision of implantation.

\section{CSF leak}

CSF gusher during the surgery was observed in 8 patients. The eight patients had CSF leakage during surgery. CSF gusher occurs due to congenital anomalies of the inner ear, one common cavity, two IP1, and five IP2. The leakage stopped spontaneously within $48 \mathrm{~h}$ of all patients.

\section{Device failure}

Device failure occurred in 2 cases due to external trauma; by imaging, there was no abnormality in the device; by impedance measurement, short circuit was seen which required re-implantation.

There was no relation to the type of incision to the rate of complications.

\section{Discussion}

In the past 20 years, cochlear implantation has made great progress. Postoperative complications have somewhat declined with the improvement of surgical equipment and techniques but they remain a Gordian knot for surgeons [8].

The cochlear implant has changed the vision for profoundly deaf adults and children. CI can enable most deafened persons to continue communicating using a speech by providing sufficient hearing sensations and can also provide the opportunity for children born deaf or deafened early in life to use speech as their primary route of communication [9].

Now it is necessary to evaluate the safety and the efficiency of such procedures to improve them and to reduce the incidence of complications. Various classifications have been introduced: early versus late complications and major versus minor complications [10].

In this study, we have a minimal rate of major complications but moderate to high rate of minor complications in relation to other studies. The overall rate of complication was $36.86 \%$. The number of major complications was 21 (16.1\%), of which $4(3.07 \%)$ patients required reimplantation, and the number of minor complications was $27(20.76 \%)$. Venail et al. [11] reported in their series that the overall rate of complication was $16 \%$, and the rate of major complications (5.6\%) was lower than that found in previous studies (18.3\%) [4]. Regarding postoperative complications, we reported that 7 cases $(5.38 \%)$ had chorda tympani injury out of 130 cases underwent cochlear implantation. 

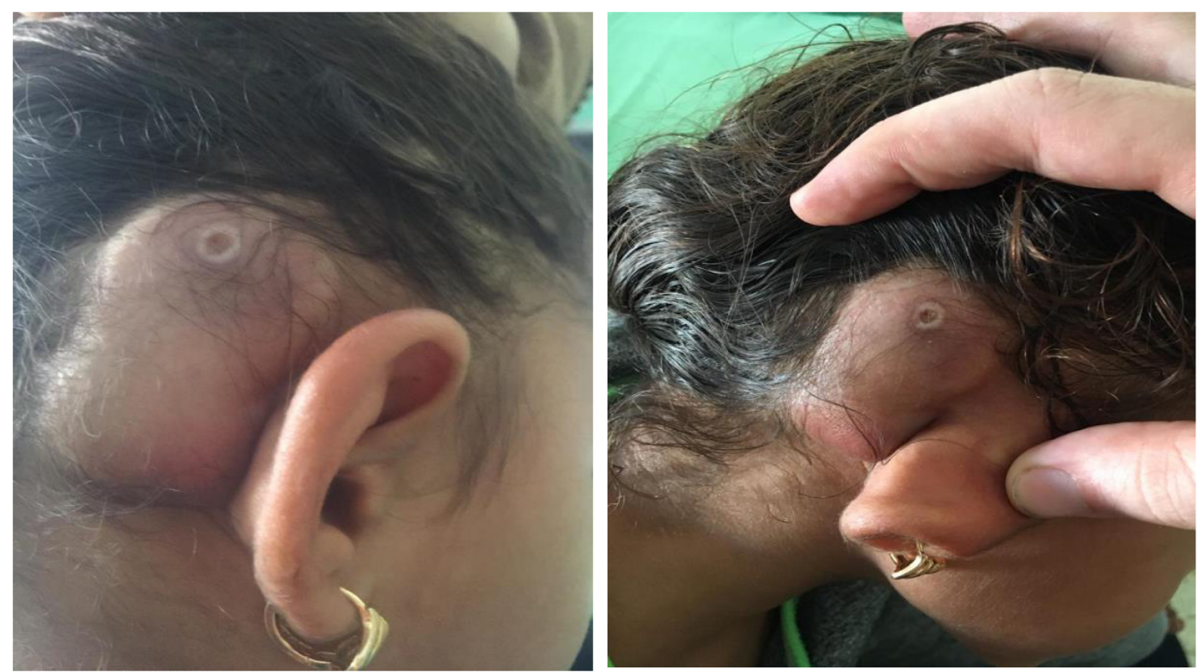

Fig. 4 Device migration after trauma

Ajalloueyan et al. [12] in a study of 262 cases operated for cochlear implantation reported 3\% of chorda tympani nerve injury. Migirov et al. [13] operated 300 cases of CI by SMA and reported one case of chorda tympani nerve injury (0.3\%). Jeppesen and Faber [14] in a study of 308 cases operated for cochlear implantation reported $30.8 \%$ of chorda tympani nerve injury. In this study, we reported 3 cases (2.3\%) had device migration out of 130 cases who underwent cochlear implantation. Kevin et al. [15] reported that out of 806 cases, the incidence of electrode migration was $9 \%$ and receiver/stimulator migration was $7 \%$. The cause of this complication is variable, but the canal wall reconstruction, split bridge technique, or tight packing around the cochleostomy window should decrease the occurrence of this complication [16]. Jonas Jeppesen and Faber [14] in a study of 308 cases reported $1.3 \%$ of electrode migration. Brito et al. [7] in a study of 550 cases reported that problems during electrode bundle insertion were the most frequent complication, happening in $21(3.8 \%)$ cases. Ajalloueyan et al. [12] in a study of 262 cases implanted using both approaches reported $2 \%$ of device migration that needed to be repositioned. In this study, out of 130 cases who underwent cochlear implantation, 5 cases $(3.8 \%)$ had total facial nerve paralysis. Paralysis was temporary in all the 5 patients and facial function became normal within 3 months of the operation. Migirov et al. [13] reported that 2 cases had facial nerve paralysis $(0.66 \%)$ out of 300 cases operated by SMA. Brito et al. [7] in a study of 550 cases reported that transient peripheral facial paralysis was the most frequent, happening to $12(2.2 \%)$ of the patients. It was immediate in nine patients and of lateonset in four. All of them had a total recovery. Ajalloueyan et al. [12] reported that in a study of 262 cases operated by both approaches, $1 \%$ had facial nerve paralysis.
In the present work, we found 2 cases $(1.5 \%)$ had a device malfunction out of 130 cases underwent cochlear implantation. Kevin et al. [15] reported that the most common reasons for revision were device malfunction. They found that $7.8 \%$ had device malfunction out of 805 cases operated by both approaches. Venail et al. [11] reported that cochlear reimplantation was performed in 36 cases $(7.2 \%$ of patients). The most common cause of reimplantation was device failure. Ajalloueyan et al. [12] reported $1 \%$ of device malfunction in 262 cases of CI. Jeyakumar and Clary [17] operated 143 cases and reported a $3.0 \%$ device failure rate in pediatric cochlear implants after a 1-year follow-up. In the present work, there were 4 cases of wound infection (3.1\%) after surgery. Ajalloueyan et al. [12] reported that, out of 262 cases, 2 cases had wound infection $(0.8 \%)$ post CI. Jeppesen and Faber [14] in a study of 308 cases reported 3.6\% of wound infection. Raghunandhan et al. [3] reported that six implantees developed flap infection out of 300 cases who underwent CI. In this study, there were 3 cases $(2.3 \%)$ who had postoperative vertigo out of 130 cases who underwent CI. Júnior et al. [18] reported 6 cases $(2.4 \%)$, out of 250 cases, who had postoperative vertigo. Migirov et al. [13] reported 28 cases, out of 300 cases, who had postoperative vertigo (10\%). Jeppesen and Faber [14] in a study of 308 cases reported $29.5 \%$ of transient vertigo. Yin et al. [19] reported 3 cases (6.6\%), out of 45 cases, who had postoperative vertigo.

In this study, there were 4 cases (3\%) who had wound hematoma out of 130 cases who underwent CI. Brito et al. [7] in a study of 550 cases reported that 3 cases $(0.5 \%)$ had wound hematoma. In this study, out of 130 cases who underwent $\mathrm{CI}$, there were 8 cases $(6.1 \%)$ that had CSF leakage during surgery. All cases had gusher during surgery due to congenital anomalies of the inner 
ear. The leakage stopped spontaneously within $48 \mathrm{~h}$ of all patients. Li et al. [20] reported that severe CSF gusher during the surgery was observed in three patients $(1.15 \%)$ in a study of 260 cases. Gheorghe et al. [21] reported that 2 gusher cases were encountered in their cochlear implant patients (79 patients). In this study, there was one case $(0.8 \%)$ that had CSOM or cholesteatoma out of 130 cases that underwent CI. Jeppesen and Faber [14] reported that one patient experienced secretion and sensation of pressure in the ear 4.5 years after implantation in a study of 308 cases. Brito et al. [7] reported that cholesteatoma appeared later in six (1.1\%) patients out of 550 patients operated for CI. Venail et al. [11] reported that three cases of cholesteatoma were observed out of 500 patients operated for CI. In this study, there were no cases that had post-implantation meningitis. Green et al. [6] reported that there are no cases of meningitis following cochlear implantation in a study of 240 cases. Ajalloueyan et al. [12] operated 262 cases and reported that $0.8 \%$ had post-implantation meningitis. Júnior et al. [18] operated 250 cases and reported that no cases had post-implantation meningitis. This is attributed according to the vaccination policy program against meningitis.

\section{Conclusion}

Cochlear implantation remains a safe and effective surgical procedure. The overall incidence of major complications is low. We have a minimal rate of major complications but moderate to high rate of minor complications in relation to other studies. The majority of minor complications can be effectively managed with conservative measures.

\section{Abbreviations}

EAC: External auditory canal; CSF: Cerebro-spinal fluid; IP1: Incomplete partition type 1; IP2: Incomplete partition type 2

\section{Acknowledgements}

Not applicable

\section{Authors' contributions}

All authors have read and approved the manuscript. AE is the main contributor in writing the manuscript. AT reviewed the manuscript. Al shared in the follow-up of the patient and collection of data. IS shared in writing the manuscript and is the corresponding author. SA analyzed and interpreted the patient data.

\section{Funding}

No funding.

\section{Availability of data and materials}

The datasets used and/or analyzed during the current study are available from the corresponding author on reasonable request.

\section{Declarations}

\section{Ethics approval and consent to participate}

Approved by IRB, Zagazig University ZU-IRB \# 5159/29-1-2019. Informed written consent to participate in the study was provided by all participants and guardians of patients under 16 years old.

\section{Consent for publication}

Written informed consent for the publication of these had been obtained from the participants' parents or legal guardians in the case of children under 16.

\section{Competing interests}

The authors declare that they have no competing interests.

Received: 27 April 2020 Accepted: 4 June 2021

Published online: 17 July 2021

\section{References}

1. Nancy Young MD, Tam Nguyen MD, Wiet R (2003) Cochlear implantation. Oper Tech Otolaryngol Head Neck Surg 14(4):263-267

2. Hehar SS, Nikolopoulos TP, Gibbin KP, O'Donoghue GM (2002) Surgery and functional outcomes in deaf children receiving cochlear implants before age 2 years. Arch Otolaryngol Head Neck Surg 128(1):11-14. https://doi. org/10.1001/archotol.128.1.11

3. Raghunandhan S, Mohan Kameswaran RS, Kumar A, Agarwal AK, Hossain MD (2014) A study of complications and morbidity profile in cochlear implantation. Indian J Otolaryngol Head Neck Surg 66(1):161-168. https:// doi.org/10.1007/s12070-011-0387-3

4. Bhatia K, Gibbin KP, Nikolopoulos TP, O'Donoghue GM (2004) Surgical complications and their management in a series of 300 consecutive pediatric cochlear implantations. Otol Neurotol 25(5):730-739. https://doi. org/10.1097/00129492-200409000-00015

5. Arnoldner C, Baumgartner WD, Gstoettner W, Hamzavi J (2003) Surgical considerations in cochlear implantation in children and adults: a review of 342 cases in Vienna. Acta Otolaryngol 125(3):228-234

6. Green KMJ, Bhatt YM, Saeed SR, Ramsden RT (2004) Complications following adult cochlear implantation: experience in Manchester. The Journal of Laryngology \& Otology 118(6):417-420. https://doi.org/10.1258/002221 504323219518

7. Brito R, Monteiro TA, Leal AF, Tsuji RK, Pinna MH, Bento RF (2012) Surgical complications in 550 consecutive cochlear implantations. Braz Otorhinolaryngol 78(3):80-85

8. Trinidade A, Rowlands G, Obholzer R, Lavy J (2008) Late skin flap failure following cochlear implantation. Cochlear Implants Int 9(3):167-175. https:// doi.org/10.1179/cim.2008.9.3.167

9. Christiansen JB, Leigh IW (2002) Cochlear implants in children: ethics and choices. Gallaudet University Press, Washington, DC, pp 253-289

10. Loundon N, Blanchard M, Roger G, Denoyelle F, Garabedian EN (2010) Medical and surgical complications in pediatric cochlear implantation. Arch Otolaryngol Head Neck Surg 136(1):12-15. https://doi.org/10.1001/archoto.2 009.187

11. Venail F, Sicard M, Piron JP, Levi A, Artieres F, Uziel A, Mondain M (2008) Reliability and complications of 500 consecutive cochlear implantations. Arch Otolaryngol Head Neck Surg 134(12):1276-1281. https://doi.org/10.1 001/archoto.2008.504

12. Ajalloueyan M, Amirsalari S, Yousefi A (2011) Report of surgical complications in a series of 262 consecutive pediatric cochlear implantations in Iran. Iran J Pediatr 21:455-460

13. Migirov L, Dagan E, Kronenberg J (2009) Surgical and medical complications in different cochlear implant devices. Otoneurology. 129:741-744

14. Jeppesen J, Faber CE (2013) Surgical complications following cochlear implantation in adults based on a proposed reporting consensus. Acta Otolaryngol 133(10):1012-1021. https://doi.org/10.3109/00016489.2013. 797604

15. Kevin D, Brown MD, Sarah S (2009) Incidence and indications for revision cochlear implant surgery in adults and children. Laryngoscope 119:152-157

16. Kronenberg J (2004) The suprameatal approach: an alternative surgical approach to cochlear implantation. Otology and Neurotology 25(1):41-45. https://doi.org/10.1097/00129492-200401000-00008

17. Jeyakumar C (2006) Device failure in pediatric cochlear implantation. Am J Otol 4:317-377

18. Júnior L, Júnior F, Calhau C, Calhau A, Palhano C (2010) Postoperative complications in implanted patients in the Cochlear Implant Program of Rio Grande do Norte - Brazil. Braz J Otorhinolaryngol 76(4):517-521. https://doi. org/10.1590/S1808-86942010000400017

19. Yin S, Chen Z, Wu Y, Wang L, Zhang J, Zhou W, Zhou W, Huang J, Shen Z Qiu J (2008) Suprameatal approach for cochlear implantation in 45 Chinese 
children. Int J Pediatr Otorhinolaryngol 72(3):397-403. https://doi.org/10.101 6/.i.jporl.2007.12.001

20. Li S, Qin Z, Zhang F, Lu L, Qi S, Liu L (2014) Early complications following cochlear implantation in children and their management. Int J Pediatr Otorhinolaryngol 78(7):1040-1044. https://doi.org/10.1016/j.jporl.2014.03.036

21. Gheorghe DC, Zamfir-Chiru-Anton A (2015) Complications in cochlear implant surgery. Journal of Medicine and Life 8(3):329-332

\section{Publisher's Note}

Springer Nature remains neutral with regard to jurisdictional claims in published maps and institutional affiliations.

Submit your manuscript to a SpringerOpen ${ }^{\odot}$ journal and benefit from:

- Convenient online submission

- Rigorous peer review

- Open access: articles freely available online

- High visibility within the field

- Retaining the copyright to your article

Submit your next manuscript at $\boldsymbol{\nabla}$ springeropen.com 